\title{
Desenvolvimento de célula para espectroeletroquímica Raman para estudos de mecanismo de reação em processos de oxidação de água
}

\author{
Matheus F. dos Santos*, Vera Katic, Pãmyla L. dos Santos, Bruno M. Pires, André L. B. Formiga, Juliano A. \\ Bonacin.
}

\section{Resumo}

Nesse trabalho, uma célula para espectroeletroquímica Raman em formato cúpula e eletrodos de trabalho foram desenvolvidos usando a tecnologia de impressão 3D, os quais foram usados no estudo de mudanças estruturais do Azul da Prússia (AP) em função do potencial aplicado.

\section{Palavras-chave:}

Impressão 3D, espectroeletroquímica Raman, célula impressa em 3D para espectroeletroquímica Raman

\section{Introdução}

A espectroeletroquímica Raman é uma ferramenta poderosa para caracterizar e entender mudanças estruturais de moléculas durante reações eletroquímicas. Medições in-situ permitem identificar sítios catalíticos e intermediários reativos, o que facilita a compreensão de mecanismos reacionais. Entretanto, uma das limitações da técnica é o alto custo da célula espectroeletroquímica (CEE). Dessa forma, a tecnologia de impressão em 3D surge como uma excelente alternativa para a produção de uma célula de qualquer geometria, de baixo custo e robusta. Nesse sentido, o objetivo desse trabalho foi desenvolver uma CEE impressa em 3D e utilizá-la no estudo espectroeletroquímico do AP.

\section{Resultados e Discussão}

A Figura 1 mostra fotos capturadas da CEE impressa em 3D com filamentos de ABS (acrilonitrila-butadienoestireno) e eletrodo de trabalho 3D usando filamentos condutivos de grafeno-PLA (poli (ácido láctico)).

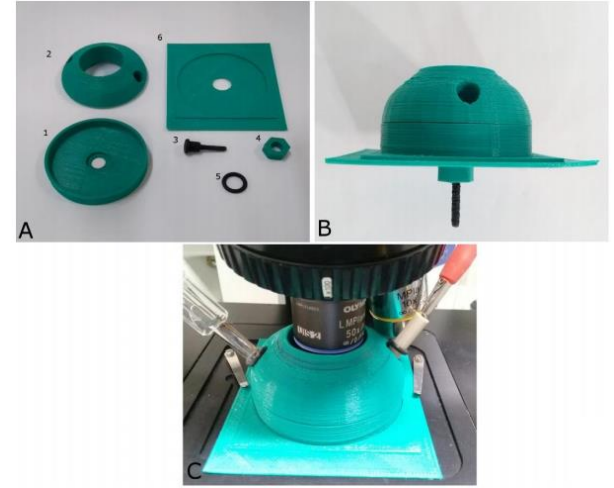

Figura 1. (A) Componentes da CEE impressa em 3D: (1) copo, (2) tampa, (3) eletrodo, (4) porca, (5) anel de borracha, (6) suporte, (B) vista lateral da célula montada, (C) célula acoplada ao equipamento Raman: eletrodo de referência à esquerda e contra eletrodo à direita.

O espectro Raman in-situ do AP no eletrodo de grafenoPLA foi obtido de $-0.5 \mathrm{~V}$ a $+1.2 \mathrm{~V} v s$. $\mathrm{Ag} / \mathrm{AgCl}$ e é mostrado na Figura 2, o qual foi limitado entre 2200 e $2000 \mathrm{~cm}^{-1}$ para investigar o deslocamento da banda característica do estiramento $\mathrm{C} \equiv \mathrm{N}, \mathrm{v}(\mathrm{CN})$, do $A P{ }^{1}$. Em $+0.2 \mathrm{~V}$ vs. Ag/AgCl ocorre a oxidação do Branco da Prússia (BP) para AP (Eq.1) e em $+0.9 \mathrm{~V}$ vs. $\mathrm{Ag} / \mathrm{AgCl}$ ocorre a oxidação do AP para Verde de Berlin (VB) (Eq.2) ${ }^{2,3}$.
$\mathrm{K}_{4} \mathrm{Fe}_{4}{ }^{\prime \prime}\left[\mathrm{Fe}^{\prime \prime}(\mathrm{CN})_{6}\right] \rightarrow \mathrm{Fe}_{4}{ }^{\prime \prime \prime}\left[\mathrm{Fe}^{\prime \prime}(\mathrm{CN})_{6}\right]_{3}+4 \mathrm{~K}^{+}+4 \mathrm{e}^{-}(1)$ $\mathrm{Fe}_{4}{ }^{\prime \prime \prime}\left[\mathrm{Fe}^{\prime \prime}(\mathrm{CN})_{6}\right]_{3}+3 \mathrm{Cl}^{-} \rightarrow \mathrm{K}_{4} \mathrm{Fe}_{4}{ }^{\prime \prime \prime}\left[\mathrm{Fe}^{\prime \prime \prime}(\mathrm{CN})_{6} \mathrm{Cl}\right]_{3}+3 \mathrm{e}^{-}(2)$

Assim, foi possível acompanhar a influência do estado de oxidação do metal na frequência de $\mathrm{v}(\mathrm{CN})$.
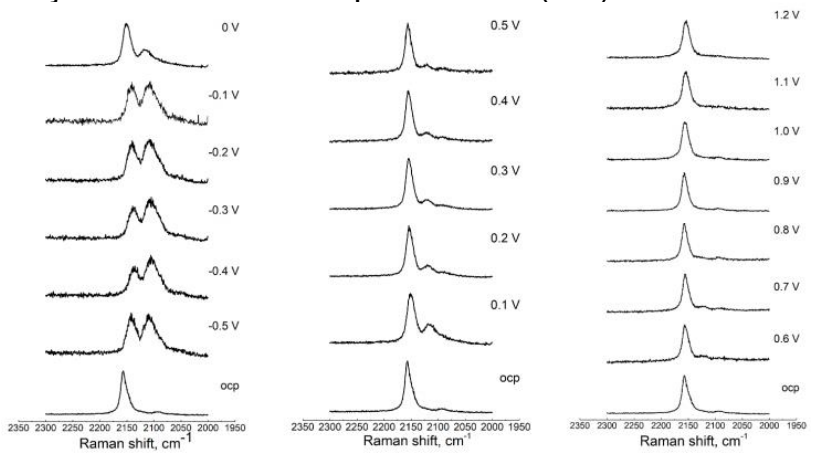

Figura 2. Espectro Raman do eletrodo de trabalho $3 \mathrm{D}$ modificado com AP obtido em potenciais de $-0.5 \mathrm{~V}$ a 1.2 $\checkmark v s$. Ag/AgCl, em comprimento de onda de excitação de $532 \mathrm{~nm}$.

O ligante cianeto nos compostos $\mathrm{BP}, \mathrm{AP}$ e VB está coordenado a íons de ferro de diferentes estados de

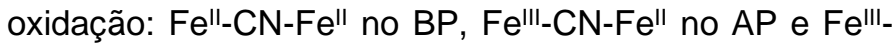
$\mathrm{CN}-\mathrm{Fe}^{\mathrm{III}}$ no VB. Isso provoca uma mudança de ambiente químico no cianeto, o que causa alterações na sua frequência vibracional ${ }^{4}$, como mostrou a Figura 2.

\section{Conclusões}

Esse trabalho demonstrou o potencial da tecnologia de impressão 3D, a qual permitiu desenvolver uma CEE simples, de baixo custo, robusta com filamentos de ABS e eletrodos de trabalho com filamentos de grafeno-PLA. A CEE 3D foi testada para medições in-situ com eletrodo de trabalho modificado com AP, onde foi possível investigar as mudanças estruturais desse composto durante o processo redox.

\section{Agradecimentos}

Os autores agradecem à CAPES, à FAEPEX-UNICAMP (\#2824/17), ao CNPq (\#459923/2014-5), ao PIBIC/CNPq, à FAPESP (\#2013/22127-2) e ao CNPq-MCT/FAPESP.

\footnotetext{
${ }^{1}$ Moretti, G. e Gervais, C. J. Raman Spectrosc. 2018, 49 (7), 1198-1204.

2 Ricci, F. e Palleschi, G. Biosens. Bioelectron. 2005, 21 (3), 389-407.

${ }^{3}$ Kong, B.; Selomulya, C.; Zheng, G. e Zhao, D. Chem. Soc. Rev. 2015, 44 (22), 7997-8018.

${ }^{4}$ Nossol, E. e Zarbin, A. J. G. J. Mater. Chem. 2012, 22 (5), 1824-1833.
} 